\title{
CORRECTION TO: CONFIGURATIONAL AXIOMS DERIVED FROM MÖBIUS CONFIGURATIONS
}

\author{
K. PETELCZYC \\ Faculty of Mathematics, University of Białystok, Ciołkowskiego 1 M, 15-245 Białystok, Poland \\ e-mail: kryzpet@math.uwb.edu.pl
}

(Received November 17, 2020; accepted November 17, 2020)

Erratum to: Acta Mathematica Hungarica 145 (2) (2015), 304-308.

DOI: $10.1007 / \mathrm{s} 10474-015-0490-0$

It was noticed that there is a misprint in the initial of the name of one of the authors in the original online version of the paper. Namely, in the author list on the first page there should be K. Petelczyc instead of P. Petelczyc.

The online version of the original article can be found under DOI: 10.1007/s10474-015-0490-0 